\title{
An e-Learning Model for Teaching Mathematics on an Open Source Learning Platform
}

\author{
Jeong Yong Ahn and Akugizibwe Edwin \\ Department of Statistics (Institute of Applied Statistics), Chonbuk National University, Korea
}

\begin{abstract}
Throughout the world, mathematics plays a vital role for the educational and developmental aspirations of any country. The quest to teach mathematical knowledge in a viable and effective way so as to induce creativity and applicability among learners is an ongoing challenge, especially for developing countries. A better understanding of how students learn mathematics coupled with effective application of mathematical e-learning can enhance meaningful learning of mathematics and make the subject more exciting. In this note, we introduce a mathematical e-learning model suitable for the modern digital era based on the learning theories of social constructivism, social realism, and connectivity. We then discuss the feasibility of implementing the model on an open source e-learning platform. Our findings reveal that the platform offers a developer's tool for coding and customizing templates to attain higher levels of usage and interactivity in which learners can create and control learning objects while they observe the results.
\end{abstract}

Keywords: assessment and feedback, dynamic and interactive content, e-learning platform, learning theory, mathematical learning model 


\section{Introduction}

E-learning practices have been incorporated in the teaching and learning processes. For effective mathematical e-learning, one needs appropriate software as well as well-known learning principles and theories to create mathematics content that fit the learners' needs and the teachers' overall intentions. In developed countries, high internet connectivity has enabled most universities and other teaching institutions to fully embrace e-learning. Nevertheless, e-learning practices are yet to attain full potential in developing countries, partly due to high initial costs of designing and setting up the platforms as well as low internet connectivity in developing countries.

To overcome the bottlenecks that impede successful and effective mathematical e-learning intervention in developing countries, e-learning implementers need to focus on three e-learning aspects, namely cost, usability, and impact on learning. Open source e-learning platform is a substantial alternative to meet these new demands. There are many open source platforms including eXelearning, Xerte Online Toolkits (XOT), and Course Builder (Berking, 2016). With these platforms, instructors can design mathematics content to suit their teaching and learning approaches. They provide a fully featured elearning development environment for creating interactive learning materials (Yi \& Trevino, 2015). In addition, the contents generated on them can easily be exported to another website or e-learning platform such as Moodle.

On the other hand, while efforts towards improving e-learning usage in developing countries are gathering pace, most of the works has been general in perspective and only few have emphasized mathematical e-learning specifically (Juan, Huertas, Cuypers, \& Loch, 2012; Namukasa, Quinn, \& Kaahwa, 2010; Elijah, 2012). Additionally, there is a big gap to fill with respect to designing new feasible mathematical e-learning models that are focused at revitalizing the interest, creativity, and applicability of mathematical knowledge for technological advancement in developing countries (Barnes \& Venter, 2008). This note is to introduce a mathematical learning model for developing countries as a suitable and effective model for the modern digital era. First, we briefly explore three vital theories of learning to be considered as the basis of the model. Next, we propose a model and discuss the feasibility of implementing the model on an open source e-learning platform. We pose the following key questions that will guide our study: (i) what are the suitable underlying theories for effective mathematical elearning in the model? And (ii) what are the key features a mathematical e-learning platform should offer that makes mathematics more discernible to learners?

\section{Underlying Theories for the Model}

Constructivism learning theory emphasizes knowledge construction based on a learner' past experience (Koohang, Riley, \& Smith, 2009). The learning approach is student centered, flexible, and accommodating multiple perceptions, content, and context (Murphy, 1997; Treffers, 1987). We need to accommodate students' ideas, views, and frustrations over the mathematical concept we want to impart unto them. In addition, we should allow all forms of creative input from the students even though they are contrary to known ideas. Based on the many useful ideas of social constructivism, we emphasize the aspect of contextualizing mathematics to fit the local settings and tap into learners informal strategies so as to motivate and induce creativity to problem solving and applicability of mathematical knowledge. 
Connectivism is concerned with linking a variety of ideas, specialized nodes, or information sources that all contribute to learning. Learning may reside in non-human appliances and learning is endless (Siemens, 2005). Relatedly, Gravemeijer, Stephan, Julie, Lin, and Ohtani (2017) observe that in the modern digital era in which computers can solve many mathematical problems, new approaches to mathematical pedagogy are necessary. They listed applying/modeling, understanding, and checking as mathematical competences required in the digital era. From these points of view, we derive the following guidelines to consider for effective mathematics learning in the digital era: Less emphasis laid on recall and reproducing knowledge (such as axioms, theories, formulae) since in the digital era, it is easy to store and extract knowledge in non-human appliances (Siemens, 2005).

The goal of realism in education is to encourage active learning that captures most of the senses of the human being (Ravi, 2016). Pedagogically, the teacher's role from the realism perspective is to pass on mathematical truth to students whose main role is to absorb the knowledge and make sense out of it. This approach was dominant before 1970 in the developed world (Young, 2008). However, unabated realism in the developing world has resulted in a teacher-centered approach, which has caused students to lag behind especially in science, technology, and mathematical application. In addition, the level of research publications in mathematics from developing countries is either very low or almost nonexistent (Barnes \& Venter, 2008; Namukasa et al., 2010; Elijah, 2012).

In summary, constructivism tells us of the importance to rely on students' experiences and context to derive knowledge and guide the learning process. There is a need to carefully link all learning nodes, especially taking advantage of present day technologies as connectivism avers. However, realism reminds us that some mathematical knowledge can be considered as absolute and powerful, and challenges us to strike a balance between absolutism and socialisation of knowledge. Constructivism, connectivity and realism essentially emphasize motivation, context, and tapping into students' abilities and experiences as the key aspects of meaningful learning but without sacrificing the power and beauty of mathematics knowledge. These ideas lead us to propose the MCIEC (motivation, context, interactivity, evaluation, and connectivity) model. The model identifies five utmost important aspects of effective mathematics learning, namely motivation, context, interactivity at the front end of lesson planning and delivery, and dynamic evaluation and connectivity at the back end of lesson planning and delivery.

\section{The MCIEC Model}

In this section, we introduce the MCIEC model which, for the trial phase, was applied to two undergraduate mathematics courses namely Linear Algebra 1 and Introduction to Probability and Statistics. We will reference materials developed in these two course units to explain the model.

\section{Motivation}

Figure 1 shows the overall structure of the MCIEC model. First, motivation is one of the three key pillars of the model. Many studies have explored the link between mathematics and motivation in terms of achievement and competence (Pokay \& Blumenfeld, 1990; Midgley, Feldlaufer, \& Eccles, 1989). In the MCIEC model, motivation focuses on the content being taught in terms of clearly manifesting the necessity of the content both in academic and practical value to the learners. A better understanding of how students learn mathematics coupled with effective application of mathematical e-learning can 
enhance meaningful learning of mathematics and make the subject more exciting (Waege, 2009; McElroy, O'Loughlin, Townsend, \& Simonovits, 2011).

Mathematics, especially at a higher level, appears abstract to students mainly because teachers put more emphasis on the process of mathematics content and put less emphasis on the necessity of the content. For example, when teaching eigenvalues, it is important for a teacher to extensively highlight on why the concept of eigenvalues is of much importance, both in academically and practically, before rushing to show how to solve for eigenvalues. As an illustration, in Lecture 1 of the course unit Linear Algebra 1, which we run, the motivation phase began by embedding a YouTube video that explains the real life applications of systems of linear equations. Students will appreciate the value of the knowledge being acquired and this can help to demystify the absoluteness and powerfulness of the knowledge. The interest will motivate the student to put more effort in learning the content and also imagine other ways of adding value to the content, which sparks creative thinking in the learners.

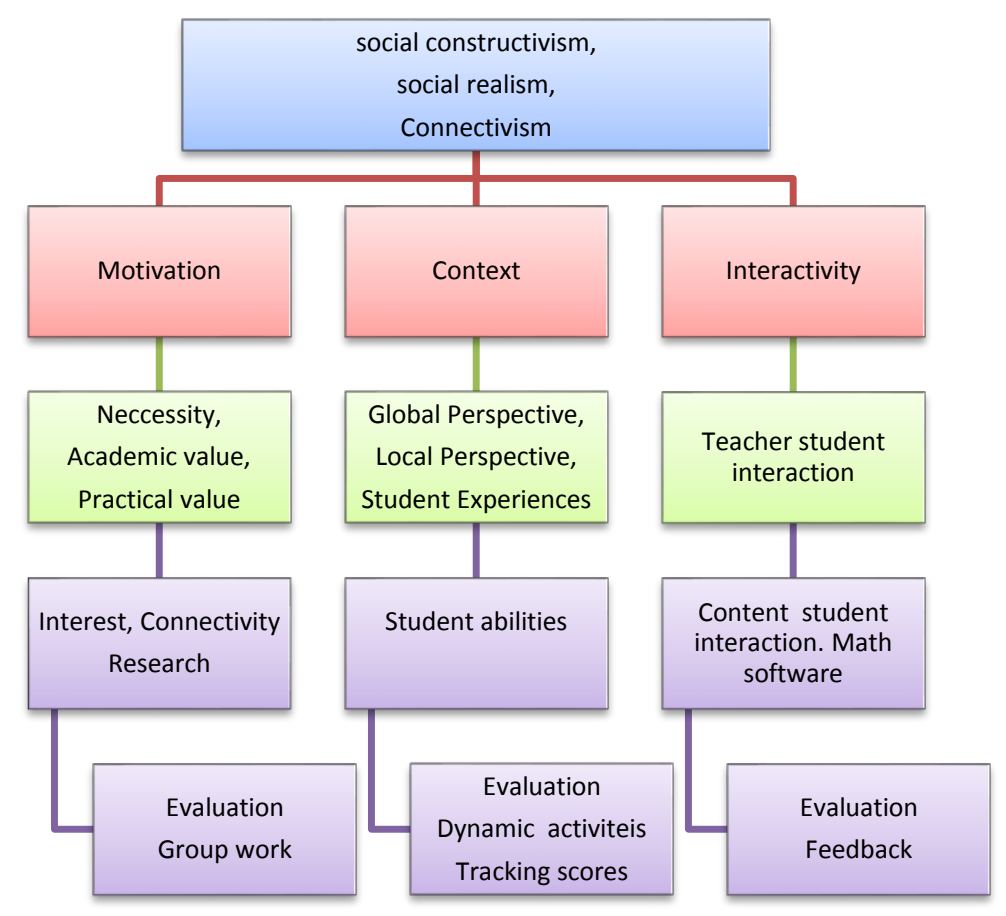

Figure 1. The structure of MCIEC model.

\section{Context}

The second key pillar of the MCIEC model is context. Koohang, Riley, and Smith (2009) view contextualization as the design of learning activities, and Perin (2011) identifies key themes of contextualization. Many studies are advocating for a form of contextualization in which much effort is spent on turning the mathematics content into a language the student clearly understands or is familiar to, so that the transition into the mathematical language of rules and symbols becomes a mere formality (Berns \& Erickson, 2001; Guthrie, Anderson, Alao, \& Rinehart, 1999; Klinger, 2011). In our model, contextualisation focuses on the need to align the content in terms of global perspective, local perspective, and students' experiences. The teacher guides in identifying world events, practices, and 
issues to relate to the content, then incorporates in local matters as well as students' experiences and abilities. As an illustration for contextualization process, we relate the content to students' previous knowledge on solving simultaneous equations. We explain some word problems involving traffic flow, merchandize, and daily shopping, and then seek individual student abilities and rely on this to sequence the explanation and activities. This form of contextualisation will spur curiosity and also help align the content to student's pace of learning.

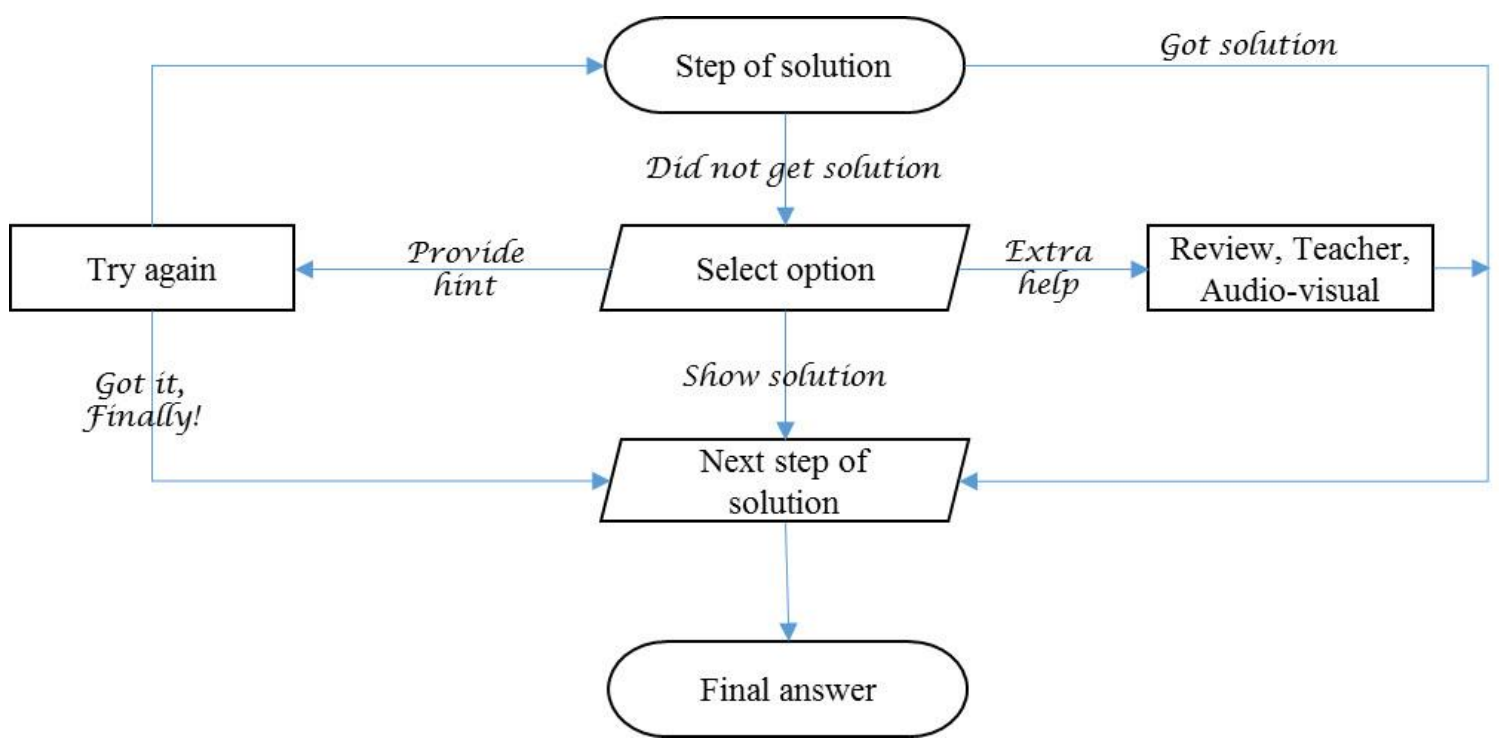

Figure 2. Flow chart for a highly interactive mathematical activity.

\section{Interactivity}

The interactivity is the coming together of the teacher, learners, and technology to facilitate the teaching and learning process. Wood and Ashfield (2008) explain that interactions between teacher, pupils, and technology necessitate more than the transmission of knowledge from either teacher or technology to learner. Figure 2 present the flow chart for supporting a highly interactive learning process in the MCIEC model. Students attempt the first step of the problem. If they get the first step, they are directed to the next step. Otherwise, they can select from three options, namely, requesting for a hint so as to try again, seeking extra help from content, using audio-visuals or teacher, and/or proceeding to the next step of the solution. Their study style will be recorded and the teacher can rely on it to provide appropriate guidance. An open platform Xerte Online Toolkits (XOT), adapted to this study, has many features that offer learners high levels of interactivity. A goal of the model MCIEC, is to create mathematical e-learning models with high interactivity, so as to stimulate the learner's own thought process, creativity, and applicability.

\section{Dynamic Evaluation}

Evaluation plays a crucial part of completing all aspects of the MCIEC model. Dynamic evaluation seeks to evaluate the learners in such a way as to cater for the learner's context, learning ability, and pace, as well innovativeness. Lui, Lo, and Yiu (2013) listed four levels of learning activities based on Bloom's taxonomy of learning domains, which are to acquire knowledge, practice and apply, explore and 
evaluate, propose, and create (Bloom, Engelhart, Furst, Hill, \& Krathwohl, 1956). The appropriate evaluation of these activities should be based on learner context, such as assessment of learning, pace of students, ability, and group versus individual contribution to activities. E-learning platforms should be designed to provide feedback, track scores, and subsequently direct the appropriate sequencing of activities to fit the learners' context.

\section{Connectivity}

This comes at the tail end of the lesson or topic. The aim is to show how the knowledge acquired by students is connected to diverse academic and practical fields. For example, we relate the knowledge of solving simultaneous equations to diverse fields, such as linear regression, electric circuits, and garbage collection. We then request students to work in groups to formulate a system of linear equations that solves any of the problems in these or other fields. Connectivity also serves as a checkpoint for the entire lesson or topic.

The MCIEC model, in summary, does not view the theories of constructivism, realism, and connectivism as antagonistic. Instead it uniquely taps into the strength of each of the theories to build a mathematical e-learning model that offers practical guidelines of mathematical e-learning pedagogy that stimulate creativity and applicability in learners. In particular, the model asserts that intrinsic motivation in higher learners of mathematics is achieved by emphasizing the academic and practical value of the mathematics content. Based on these aspects, the MCIEC approach can make the mathematics content less abstract and more user-friendly, while allowing for the different talents that learners possess to flourish, enabling them to develop creative, innovative, and adaptable students.

\section{Key Functional Features of the Model}

In order to successfully implement the mathematics learning model, the MCIEC model emphasizes the following functional features.

\section{Math Text and High Interactivity}

One special feature of mathematics is that it has its own language and symbols distinct from other nonmathematical subjects. An effective mathematics e-learning platform must be able to accommodate mathematical language and symbols. It should also enable lecture notes taking on the system, making it a one stop e-learning system. The platform should also have features that enable teachers to set up mathematical activities and problems in such a way that students can follow step-by-step procedures in a dynamic and highly interactive way.

Figure 3 is an example to explain how we can create a highly interactive process with math text. Students are supposed to solve the problem by inserting answers in the boxes. In an interactive e-learning system, a complement should appear once the number inserted in by the student is a correct one and the student will be encouraged to go to the next step. If the answer is incorrect, a hint is provided immediately and the student can be provided with options to get extra review, audio-visual help, peer support, or teacher support. In this way, both the student and the teacher will know which steps were most challenging to the learner. 


\section{al Intro. Stat}

Example 2.7 Let $X$ be a normal random variable with $\mu=66$ and $\sigma^{2}=16$.

Find $P(62 \leq X \leq 70)$.

$P(62 \leq X \leq 70)=\int_{62}^{70} f(x ; \square, \square) d x$

$=P\left(\frac{\square}{\square} \leq \frac{X-66}{4} \leq \bar{\square}\right)$

$=P(\square \leq Z \leq \square)=$

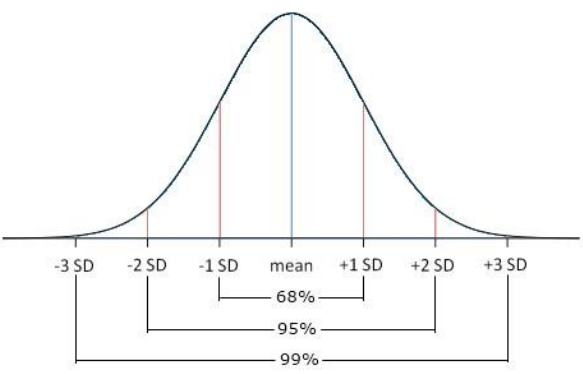

Figure 3. A highly interactive process with math text.

\section{Enable Effective Assessment and Feedback}

In both traditional and e-learning methods, assessment and feedback in the context of mathematics teaching and learning is the most effective instruction tool (Warden, 2000; Anderson et al., 2001). Assessment in mathematics needs to be well structured and sequenced. Tempelaar, Kuperus, Cuypers, Kooij, Vrie, and Heck (2012) stated that for effective mathematical assessment, all problems should produce authentic input from students arising from a carefully designed repertoire of items. It should ensure a comprehensive coverage of the domain and allow for adaptive assessment, in which the choice of a new question is based on the student's previous responses. This kind of assessment ensures that learner's capabilities and experiences are catered for and the student is asked only a small but relevant subset of questions. 
Question 1 of 2

Work out these problems and select the correct anwser

$$
\begin{gathered}
x-2 y+3 z=-2 \\
-x+y-2 z=3 \\
2 x-y+3 z=-7
\end{gathered}
$$

$$
x=-4-t, y=-1+t, z=t
$$

$$
x=2, y=5, \quad z=4
$$

No solution

Figure 4. An example of multiple choice questions.

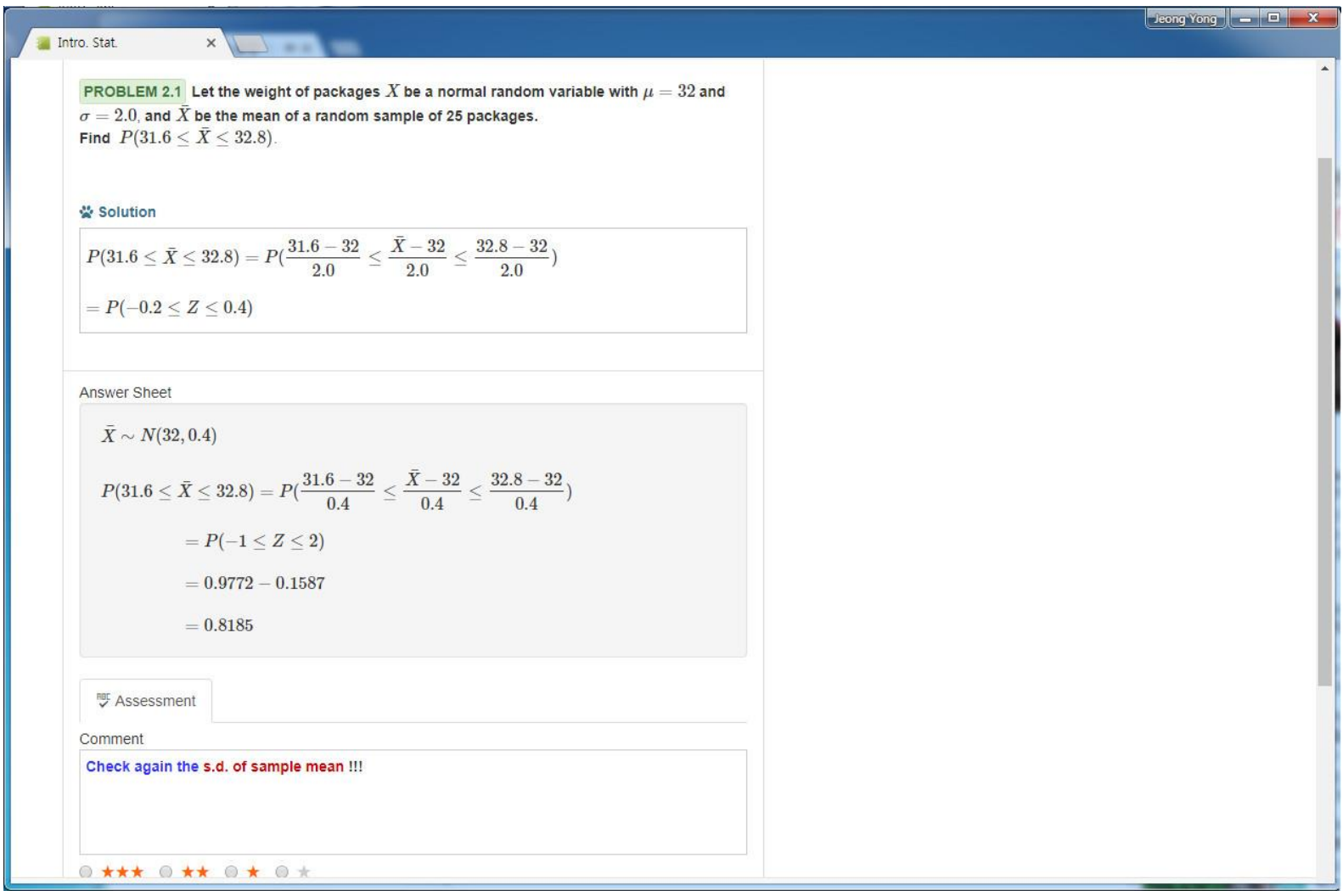

Figure 5. An example of peer-assessment and feedback. 
Figure 4 is an example of the multiple choice quizzes. Student gets immediate automatic feedback and then is prompted to go to the next question. However, it is not enough for feedback to be auto-generated by a computer program. We provide a problem in which the teacher or fellow student provides the enlightened assessment and feedback. Figure 5 shows an example of peer-assessment. A student submits the full solution and gets an assessment and feedback from the instructor and/or other students. This ensures that instructor and other students are fully involved in the feedback and assessment process. In this way, students have a platform that can automatically generate hints and feedback, but also incorporate hints and feedback generated by the instructor.

\section{Incorporate Many Offline and Online Mathematics Tools and Content}

In designing effective mathematical e-learning platforms, we must be aware of and incorporate many useful offline and online mathematical tools such as tools for mathematical typesetting and generating reports such as Latex/Share latex, R-Markdown, and Shiny. Others are tools such as Maple, Mathematica, and Matlab for computations. The trend is to have a one-stop mathematical e-learning environment, which should give a learner a laboratory experience that will facilitate the independent development and testing of problem solving strategies, incorporating typical problems of mathematics, physics, and engineering science in order to prepare the student for his or her professional life (Jeschke, Richter, \& Seiler, 2005).

\section{Conclusion}

In this study, we propose a mathematical e-learning model MCIEC, for making mathematical learning more interesting, meaningful, and applicable to the learners beyond the classroom knowledge. The teaching of mathematics beyond the primary level in most developing countries mainly emphasizes preparing students for high-stake national exams rather than linking the content to real life problem solving skills. The curricula are not well-aligned to the needs or abilities of the majority of learners and the failure rates for mathematics are extremely high (Namukasa et al., 2010). To overcome these challenges, the MCIEC model emphasizes a flexible approach to teaching mathematics in which motivation, context, and dynamic evaluation are the backbone of any content design or delivery. The model places greater responsibility to the teachers to be more innovative and create materials that suit the learners' abilities and environment. In addition, the model requires teachers to accord more time and effort on explaining the relevancy of the mathematics content before moving onto the mathematics in the content. It is easier for the student to put in much effort to understand the mathematics in the content once the interest, motivation, and context has been attained.

On the other hand, many developing countries do not have enough technological circumstance for constructing an e-learning environment. One way to overcome this problem is to use open source platforms. We employed the open platform XOT for instantiating the MCIEC model in this study. The platform offers several functionalities to create dynamic and interactive content that can provide students a richer learning experience. The platform can be used both online and offline, thereby overcoming the problem of limited and intermittent internet prevalent in most developing countries.

An evaluation of the trial phase of the model was carried out. The students' responses and instructors' observations show that the MCIEC model based on the XOT e-learning platform has proven to be an interesting and effective learning environment. Instructors pointed out immediate feedback about 
students' understanding as their favorite functionality of the environment, and students responded that they achieve enhanced understanding. In particular, the groups of students reported using considerably less time (average $=5.2$ minutes, standard deviation $=2.1$ minutes) to understand and solve problems that tested application compared to groups of students that didn't use the model. Based on this, we firmly believe the environment gives both teachers and students a rich flexible learning environment to spur creativity and applicability of mathematics knowledge.

For further development of the model, materials will be developed using XOT and several Moodle plugins such as the Formulas question type so as to fully utilize all the features of the model and create an enhanced learning experience for the learners. The model will be implemented in a rural based university in Uganda and periodical surveys carried out to further evaluate the model in comparison to other previously used models. More teachers will be trained on how to fully implement the model and user guidelines will be prepared.

\section{Acknowledgments}

This paper was supported by research funds of Chonbuk National University in 2017. This work was also partially supported by the National Research Foundation of Korea (NRF) grant funded by the Korea government (MSIP) (NRF-2016R1A2B1010253). 


\section{References}

Anderson, L. W., Krathwohl, D. R., Airasian, P. W., Cruikshank, K. A., Mayer, R. E., Pintrich, P. R. ... Wittrock, M. C. (2001). A taxonomy for learning, teaching, and assessing: A revision of Bloom's Taxonomy of Educational Objectives. New York: Longman.

Barnes, H., \& Venter, E. (2008). Mathematics as a social construct: Teaching mathematics in context. Pythagoras, 68, 3-14. DOI: 10.4102/pythagoras.voi68.62

Berking, P. (2016). Choosing authoring tools: Advanced distributed learning (ADL) initiative. Retrieved from https://www.adlnet.gov/public/uploads/ChoosingAuthoringTools.docx

Berns, R. G., \& Erickson, P. M. (2001). Contextual teaching and learning: Preparing students for the new economy. The Highlight Zone: Research @ Work 5, 1-8. Retrieved from http://citeseerx.ist.psu.edu/viewdoc/download?doi=10.1.1.453.3887\&rep=rep1\&type=pdf

Bloom, B. S., Engelhart, M. D., Furst, E. J., Hill, W. H., \& Krathwohl, D. R. (1956). Taxonomy of educational objectives: The classification of educational goals. Handbook I: Cognitive domain. New York: David McKay Company.

Elijah, E. U. (2012). E-learning and teacher preparation in science and mathematics: The paradigm for utilization of interactive packages. European Scientific Journal, 8(13), 172-177. Retrieved from https://eujournal.org/index.php/esj/article/view/204

Gravemeijer, K., Stephan, M., Julie, C., Lin, F., \& Ohtani, M. (2017). What mathematics education may prepare students for the society of the future? International Journal of Science and Mathematics Education, 15(1), 105-123. DOI: https://doi.org/10.1007/s10763-017-9814-6

Guthrie, J. T., Anderson, E., Alao, S., \& Rinehart, J. (1999). Influences of concept oriented reading instruction on strategy use and conceptual learning from text. The Elementary School Journal, 99(4), 343-366. DOI: https://doi.org/10.1086/461929

Jeschke, S., Richter, T., \& Seiler, R. (2005). Mathematics in virtual knowledge spaces: User adaption by intelligent assistants. Proceedings of the International Conference on Multimedia and ICTs in Education, 1-5. DOI: 10.4018/978-1-59140-878-9.cho11

Juan, A. A.., Huertas, M. A., Cuypers, H., \& Loch, B. (2012). Mathematical e-learning. Universities and Knowledge Society Journal, 9(1), 278-283. Retrieved from https://link.springer.com/content/pdf/10.7238/rusc.vgi1.1431.pdf

Klinger, C. M. (2011). Connectivism: A new paradigm for the mathematics anxiety challenge? Adult Learning Mathematics, 6(1), 7-19. Retrieved from https://files.eric.ed.gov/fulltext/EJ1068259.pdf

Koohang, A., Riley, L., \& Smith, T. (2009). E-learning and constructivism: From theory to application. Interdisciplinary Journal of E-Learning and Learning Objects, 5, 91-109. DOI: https://doi.org/10.28945/66 
Lui, R. W. C., Lo, K. K. Y., \& Yiu, S. M. (2013). Evaluating and adopting e-learning platforms. International Journal of e-Education, e-Business, e-Management and e-Learning, 3(3), 229233. DOI: 10.7763/IJEEEE.2013.V3.229

McElroy, J., O'Loughlin, J., Townsend, C., \& Simonovits, R. (2011). Mathematics: e-learning and math projects for students and teachers across Europe. Retrieved from http://www.zst.edu.pl/pdf/projekty/Comenius2011-2013/artykuly/Artykul\%209.pdf

Midgley, C., Feldlaufer, H., \& Eccles, J. S. (1989). Student/teacher relations and attitudes towards mathematics before and after transition to junior high school. Child Development, 6o, 981992. DOI: $10.2307 / 1131038$

Murphy, E. (1997). Constructivism: From philosophy to practice. Retrieved from https://files.eric.ed.gov/fulltext/ED444966.pdf

Namukasa, K. I., Quinn, M., \& Kaahwa, J. (2010). School mathematics education in Uganda: Its successes and its failures. Procedia Social and Behavioral Sciences, 2, 3104-3110. DOI: https://doi.org/10.1016/j.sbspro.2010.03.473

Perin, D. (2011). Facilitating student learning through contextualization. Community College Review, 39(3), 268-295. DOI: https://doi.org/10.1177/o091552111416227

Pokay, P., \& Blumenfeld, P. C. (1990). Predicting achievement early and late in the semester: The role of motivation and use of learning strategies. Journal of educational psychology, 82, 41-50. DOI: doi.apa.org/journals/edu/82/1/41.pdf

Ravi, V. (2016). Curriculum development. India: Laxmi book Publication.

Siemens, G. (2005). Connectivism: A learning theory for the digital age. International Journal of Instructional Technology \& Distance Learning. 2(1), 3-10. Retrieved from http://citeseerx.ist.psu.edu/viewdoc/download?doi=10.1.1.87.3793\&rep=rep1\&type=pdf

Tempelaar, D. T., Kuperus, B., Cuypers, H., Kooij, H., Vrie, E., \& Heck, A. (2012). The role of digital, formative testing in e-learning for mathematics: A case study in the Netherlands. Universities and Knowledge Society Journal, 9(1), 284-305. DOI: https://doi.org/10.7238/rusc.v9i1.1272

Treffers, A. (1987). Three dimensions: A model of goal and theory description in mathematics instruction - The Wiskobas project. Boston: Kluwer Academic Publishers.

Waege, K. (2009). Motivation for learning mathematics in terms of needs and goals. Proceedings of the CERME, 6, 84-93. Retrieved from http://ife.ens-lyon.fr/publications/editionelectronique/cerme6/wg1-06-waege.pdf

Warden, C. A. (2000). EFL business writing behaviors in differing feedback environments. Language Learning, 5o(4), 573-616. DOI: 10.1111/0023-8333.00141

Wood, R., \& Ashfield, J. (2008). The use of the interactive whiteboard for creative teaching and learning in literacy and mathematics: A case study. British Journal of Educational Technology, 39(1), 84-96. DOI: 10.1111/j.1467-8535.2007.00699.x 
Yi, T., \& Trevino, J. (2015). Tools for creating learning environments. Proceedings of the International Conference on Computer Supported Education, 31-37. Retrieved from http://www.wseas.us/e-library/conferences/2015/Michigan/COEN/COEN-04.pdf

Young, M. (2008). From constructivism to realism in the sociology of the curriculum. Review of Research in Education, 32(1), 1-28. DOI: 10.3102/0091732X07308969 